\title{
ENTENDENDO O GUANXI E SUA INFLUÊNCIA NAS RELAÇÕES INTERNACIONAIS*
}

\author{
Janaina Mortari Schiavini ${ }^{a}$ \\ Flavia Luciane Scherer ${ }^{b}$ \\ Daniel Arruda Coronel ${ }^{c}$
}

RESUMO: A influência do crescimento econômico chinês em nível global vai além dos impactos econômicos e financeiros nos países. As organizações que realizam Investimento Direto Estrangeiro na China e as empresas chinesas que investem no exterior lidam com um aspecto em comum: o guanxi. Enquanto "o que você sabe" é valorizado na cultura ocidental, na China a ênfase está em "quem você conhece", ou seja, nas conexões sociais com autoridades e outros indivíduos. Este estudo tem como objetivo proporcionar um esclarecimento teórico sobre o que é guanxi, evidenciando as suas origens na China, as principais características intrínsecas do construto e como um ocidental pode desenvolver guanxi, tornando-o um ativo intangível para a sua organização. Além disso, algumas pesquisas que comprovam a relação do guanxi com os fluxos de IDE, com o desempenho empresarial e com os modelos de financiamento no Brasil foram apresentadas.

PALAVRAS-CHAVE: Guanxi; China; relacionamento.

CLASSIFICAÇÃo JEL: F59.

\footnotetext{
* Artigo recebido em 20/05/2012 e aprovado em 06/08/2012.

${ }^{a}$ Mestranda do Programa de Pós-Graduação em Administração da Universidade Federal de Santa Maria (UFSM). Contato: janaina.schiavini@gmail.com.

${ }^{\text {b }}$ Doutora em Administração pela Universidade Federal de Minas Gerais e professora adjunta do Programa de Pós-Graduação em Administração da UFSM. professora adjunta Programa de Pós-Graduação em Administração da UFSM. Contato: flaviascherer@globo.com.

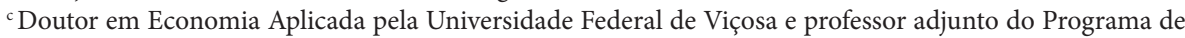
Pós-Graduação em Administração da UFSM. e professor adjunto do Programa de Pós-Graduação em Administração da UFSM. Contato: daniel.coronel@uol.com.br.
} 


\title{
UNDERSTANDING GUANXI AND ITS INFLUENCE ON INTERNATIONAL RELATIONS
}

\begin{abstract}
The influence of Chinese economic growth at the global level goes beyond the financial and economic impacts in the countries. The organizations that carry out Foreign Direct Investment (FDI) in China and Chinese companies investing abroad deal with one thing in common: guanxi. While "what you know" is valued in Western culture, in China the emphasis is on "who you know", ie, the social connections with authorities and others. Therefore, this study aims to provide a theoretical clarification about what is guanxi, showing its origins in China, the main intrinsic characteristics of the construct, and how a Westerner can develop guanxi, making it an intangible asset to your organization. Furthermore, some studies that show the relationship between guanxi with FDI flows, corporate performance and financing models in Brazil were presented.
\end{abstract}

KEYWORDS: Guanxi; China; relationship. 


\section{INTRODUÇÃO}

Aliado à tendência da globalização e o rápido desenvolvimento econômico dos países no Oriente, principalmente a China, as relações comerciais entre os países ocidentais e orientais estão sendo o foco de interesse tanto no discurso acadêmico, quanto no discurso profissional. A ascensão econômica da China tem sido um dos fatos mais marcantes do começo do século XXI, e seus possíveis efeitos sobre o sistema internacional têm atraído a atenção de diversos especialistas (Cunha et al., 2011).

A China vem recebendo volumes crescentes de Investimento Direto Estrangeiro (IDE) sob a forma de novos projetos de instalação de empresas e dirigidos majoritariamente para a indústria de transformação, particularmente para as atividades de maior valor agregado. Além disso, o país também vem apresentando altos índices de IDE em diversos países. No Brasil, por exemplo, parte significativa dos investimentos chineses anunciados em 2010 foi em fusões e aquisições (US\$ 13,09 bilhões, dos US\$ 17,17 bilhões totais), sendo 75,4\% na região sudeste (RENAI, 2012).

Com as altas taxas de crescimento econômico da China, observa-se uma nova mudança nas relações econômicas internacionais, qual seja, a China constituindo-se um novo ator com poder econômico, político e militar capaz de influenciar a geopolítica mundial e ser um dos protagonistas da nova ordem econômica, pós-queda da União das Repúblicas Socialistas Soviéticas (URSS), o que corroborou para o multilateralismo econômico, político e cultural entre as nações (Fiori, 2007).

Nesse cenário, existe uma característica cultural chinesa muito importante no contexto econômico, social e político: o guanxi. Enquanto a concepção de "o que você sabe" é valorizada na cultura ocidental, referindo-se à especialização tecnológica e à qualidade do produto ou serviço, na sociedade chinesa a ênfase está em “quem você conhece”, ou seja, nas conexões sociais com autoridades e outros indivíduos (Zhang e Pimpa, 2010). A moderna sociedade chinesa ainda opera dentro dos domínios de inúmeras redes de guanxi sociais e empresariais, influenciando a busca de oportunidades de negócios e a consolidação das empresas estrangeiras na China, já que as regras do direito há muito tempo são ausentes na China para a proteção dos direitos de propriedade privada e dos interesses econômicos (Lee, 2010).

Assim, é fundamental para as empresas na China, sejam locais ou estrangeiras, compreender e utilizar corretamente o guanxi para ganhar uma vantagem sobre os concorrentes. De acordo com Davies et al. (1995), guanxi refere-se a um tipo especial de relações ou conexões sociais com base em interesses e benefícios mútuos, em que as relações entre parceiros acontecem por meio de obrigações recíprocas e troca de favores.

No estudo do guanxi, são encontradas diversas abordagens de análise. Uma delas é apresentada por Lo e Otis (2003), que propõem que seja necessário reconhecer o 
potencial político do guanxi em termos de sua dupla tendência em direção à publicização e à privatização do poder. O desenvolvimento da civilidade do guanxi sugere as diversas origens culturais de civilidade e serve como um lembrete das raízes particularistas no pressuposto universalista da civilidade ocidental.

A partir do exposto, este estudo tem como objetivo proporcionar um esclarecimento teórico sobre o que é guanxi, evidenciando suas origens na China, as principais características intrínsecas do conceito e como um ocidental pode desenvolver guanxi, tornando-o um ativo intangível importante para a organização. Esta pesquisa foi motivada pela constatação do pequeno número de artigos publicados sobre o assunto na língua portuguesa ${ }^{1}$.

O presente trabalho está estruturado em quatro seções, além desta introdução. $\mathrm{Na}$ segunda seção, apresenta-se o que significa guanxi, buscando-se entender as suas origens no confucionismo, os principais traços intrínsecos ao conceito e as dimensões do construto que possibilitam a sua mensuração; na terceira, é abordado como o guanxi pode tornar-se um ativo intangível de uma organização, uma vez que é praticado essencialmente entre indivíduos em um contexto social. Posteriormente, na seção quatro apresenta-se o modelo de Chen e Chen (2004) sobre como desenvolver o guanxi mesmo sendo um estrangeiro. Por fim, são apresentadas as considerações finais, apresentando as limitações da pesquisa e sugestões de estudos futuros.

Embora a ideia sobre "o que você sabe" seja enfatizada na cultura ocidental, referindo-se ao conhecimento tecnológico, preço e qualidade do produto ou serviço, o destaque nas sociedades de Confúcio é sobre "quem você conhece", referindo-se a ligações pessoais com as autoridades competentes ou indivíduos (Zhang e Pimpa, 2010). Essas conexões são conhecidas em chinês como guanxi, uma característica marcante que ajuda a entrar no mercado chinês.

A noção de guanxi é profundamente enraizada na tradição chinesa há milhares de anos. É um conceito incorporado na teoria social de Confúcio e que tem sua própria lógica na formação e constituição da estrutura da sociedade chinesa (Luo, 2001). De acordo com o autor (Luo, 2001), guanxi foi definido como: (1) conexões de determinada natureza entre duas pessoas ou duas partes, (2) um estado de funções mútuas e impactos mútuos entre as coisas e (3) links ou envolvimento. Para Luo (1997), guanxi refere-se ao conceito de desenho em conexões a fim de garantir favores nas relações pessoais. É uma rede relacional que os chineses cultivam energicamente.

\footnotetext{
${ }^{1}$ De acordo com uma busca no banco de dados do portal Scielo em maio de 2012, há apenas dois artigos em português com a sobre guanxi (Sheng, 2008; Pinheiro-Machado, 2011). Na base de dados Web of Science, há somente quatro artigos brasileiros sobre o assunto, publicados em inglês, porém nenhum deles específico sobre guanxi. Por isso, este artigo pretende contribuir com uma revisão de literatura sobre guanxi, com base nas publicações estrangeiras mais relevantes, principalmente asiáticas.
} 
A palavra guanxi é composta de dois caracteres chineses, Guan (portão) e xi (conexão). Isto significa que é preciso passar do "portão" para se conectar as redes de relacionamento. Como tal, guanxi geralmente se refere a relacionamentos ou ligações sociais com base em interesses e benefícios mútuos (Yang, 1994). De acordo com Chen (1995), é um tipo especial de relação que une os parceiros de troca por meio de obrigações recíprocas para obtenção de recursos através de uma cooperação contínua e troca de favores.

As questões sobre o que de fato é guanxi e como ele funciona na prática tornaram-se tema relevante nas discussões acadêmicas e profissionais. Guanxi, literalmente, significa relação ou relações, laços ou conexões, e isso já estabelece a base sobre a compreensão da abordagem chinesa para a construção de redes sociais e relações comerciais (Zhang e Pimpa, 2010).

O confucionismo exerceu uma influência fundamental sobre os modos chineses de pensar e a maneira de se comportar. Por isso, não é de estranhar que o guanxi esteja incorporado nesta influência, e assim esteja profundamente enraizado na mente dos chineses em todos os aspectos de suas interações pessoais e organizacionais (Park e Luo, 2001). A base dessas relações também encontra-se presentes em outros países asiáticos além da China, como o Japão, Coreia, Taiwan e Cingapura.

No contexto dos negócios, guanxi abrange o uso de amigos e colaboradores em uma rede de intermediários para auxiliar nas atividades gerais de negócios (Yeung e Tung, 1996). Socializar é amplamente utilizado para a finalidade de desenvolver e fomentar a confiança mútua e o afeto entre os parceiros de negócios para que os relacionamentos possam evoluir a longo prazo (Wong e Leung, 2001). Desenvolver guanxi com autoridades do governo, por exemplo, também é considerado importante, já que pode ajudar a contornar e superar obstáculos legais e administrativos ou servir como mecanismo para proteger a empresa contra riscos imprevistos (Dunfee e Warren, 2001).

Em sociedades influenciadas pela cultura chinesa, existem formas diferentes de praticar o guanxi. Enquanto alguns podem ter uma influência positiva no desempenho dos negócios e da eficiência econômica, outros podem ajudar uma empresa individual para garantir sua posição no mercado, mas danificar os processos institucionais. De acordo com Yen et al. (2011), o "lado escuro" do guanxi, também existe, e refere-se às preocupações éticas associadas à condução dos negócios dessa maneira. Tal como acontece com as estratégias, é responsabilidade da empresa avaliar a ética e o impacto das suas decisões ao fazer uso do guanxi.

Por isso, o guanxi não deve ser utilizado como uma estratégia para alterar ou quebrar as regras de negócio. Ao invés disso, ele deve ser considerado apenas como uma alternativa para suavizar o progresso do negócio dentro de limites legais (Chen, 2001). 
Assim, apesar de a política de "porta dos fundos” fazer parte da prática do guanxi, não é incentivado que as empresas ocidentais pratiquem isso, devido aos efeitos negativos que possam causar (Dunfee e Warren, 2001).

\subsection{AS ORIGENS DO GUANXI NO CONFUCIONISMO}

Embora as conotações do guanxi possam mudar ao longo do tempo dentro de uma dada sociedade oriental, ainda é possível traçar alguns dos seus significados fundamentais nas antigas filosofias chinesas, especialmente no confucionismo. King (1991) alega que, como expressão relativamente moderna, a palavra guanxi não é encontrada nos clássicos confucionistas, ao invés disso, lun é palavra é usada. O termo literal lun é pouco conhecido atualmente na sociedade em geral chinesa; no entanto, capta alguns dos aspectos mais essenciais do sistema chinês e sua filosofia política e moral. Ao explicar o significado de lun é possível, portanto, compreender sobre as origens históricas do guanxi (Chen e Chen, 2004).

O primeiro significado diz respeito à importância primordial das relações humanas. O pressuposto fundamental de Confúcio sobre a espécie humana é o de que os indivíduos existem em relação aos outros. Dentro da grande variedade de relacionamentos, os mais importantes eram conhecidos como as Cinco Relações Cardeais ( $w$ u lun): soberano e subordinado, pai e filho, marido e mulher, irmão mais velho e irmão mais novo, e amigo sênior e amigo júnior. Embora a estrutura e a natureza dos relacionamentos possam ter evoluído desde a época de Confúcio, as modernas sociedades chinesas (no continente ou no estrangeiro) permanecem orientadas para os relacionamentos (Redding e Wong, 1986).

O segundo significado de lun é a ordem social ou, de acordo com Fei (1992), ordem diferenciada. Análoga à ordem natural, a ordem social ou a estabilidade reside na diferenciação, o que pode ser interpretado hierarquicamente e horizontalmente. Na diferenciação hierárquica, os membros de cada relação gozam de direitos e obrigações desiguais de modo que o soberano, o pai, o marido, o irmão mais velho e o amigo sênior têm mais prerrogativas e autoridade do que o subordinado, o filho, a esposa, o irmão mais novo e o amigo júnior. Na situação de família tradicional, a proximidade é baseada em laços de sangue, como membro da família, membro do clã, parentes próximos e parentes distantes. Nesta estrutura, os direitos e obrigações dos outros diferem de acordo com as posições relativas dos círculos sociais (Chen e Chen, 2004).

As prescrições confucionistas de relações sociais surgiram para colocar demandas conflitantes sobre o indivíduo chinês. Exceto para as relações pré-determinadas, como pai e filho, em que os comportamentos e as responsabilidades são, em grande parte, 
fixados, o indivíduo seguidor do Confúcio tinha uma considerável liberdade para decidir se entrava ou não em relações voluntariamente construídas fora da estrutura familiar (King, 1991). Nesse sentido, o confucionismo é o iniciador de comunicação social e o arquiteto na construção de relações.

\subsection{OS TRAÇOS DO GUANXI}

De acordo com Dunning e Kim (2007), a obra mais completa sobre os principais traços característicos do guanxi é a de Luo (2001). Este autor defende, de acordo com a sua investigação, que o guanxi possui seis traços importantes: (1) utilitarista, (2) recíproco, (3) transferível, (4) pessoal, (5) de longo prazo e (6) intangível.

O primeiro refere-se à sua essência utilitarista. O guanxi liga duas pessoas por meio da troca de favores ao invés da troca de sentimentos. Esta relação não tem que envolver amigos; no entanto, sempre que possível isso é preferido. O segundo estabelece a relação de reciprocidade na troca de favores. As relações estabelecidas por meio do cumprimento das obrigações recíprocas tendem a ser vistas como perpétuas. Todavia, é importante ressaltar que o guanxi não é necessariamente igualmente recíproco, pois na maioria das vezes as relações de troca tendem a favorecer o parceiro mais fraco.

Em terceiro lugar, Luo (2001) defende que o guanxi é transferível. Se o individuo A tem guanxi com o indivíduo B e B é amigo de C, então B pode introduzir ou recomendar A para $\mathrm{C}$ ou vice versa. A extensão e o sucesso da transferência de guanxi dependem principalmente do nível de satisfação que B sente sobre o seu guanxi com A e C.

O quarto traço refere-se ao guanxi como um conceito muito pessoal, ou seja, opera-se essencialmente entre indivíduos. Seus ingredientes essenciais são a confiança, a honestidade, a reciprocidade, o respeito e o status social. Isso explica porque a lealdade interpessoal é muitas vezes mais importante do que a afiliação organizacional ou $\mathrm{p}$ status legal na sociedade chinesa.

O quinto e importante traço do guanxi é a sua orientação de longo prazo. Todo relacionamento guanxi é considerado um estoque de capital relacional que deve ser conservado em tempos de abundância e fartura, mas mobilizados em momentos de necessidade. É desenvolvido e reforçado por meio de contínuas associações e interações interpessoais de longo prazo.

Por fim, Luo (2001) afirma que o guanxi é um ativo intangível. Pessoas que compartilham guanxi estão comprometidas uma com as outras por um código informal e não escrito de confiança, tolerância, reciprocidade e equidade. O desrespeito a essas virtudes pode danificar a respeitabilidade e as posições sociais dos indivíduos. A Tabela 1 resume os seis traços característicos do guanxi. 
Tabela 1 - Os traços do guanxi

\begin{tabular}{l|l}
\hline \multicolumn{1}{c|}{ Traços } & \multicolumn{1}{c}{ Descrição } \\
\hline Utilitarista & Guanxi é propositalmente impulsionado por interesses pessoais \\
\hline Recíproco & A reputação de um indivíduo relaciona-se às suas obrigações recíprocas \\
\hline Transferível & Guanxi é transferível por meio de um terceiro como referência \\
\hline Pessoal & Guanxi é estabelecido entre indivíduos \\
\hline De longo prazo & Guanxi é mais forte quando cultivado em longo prazo \\
\hline Intangível & Guanxi é mantido por um compromisso tácito \\
\hline
\end{tabular}

Fonte: Dunning e Kim (2007, p. 331).

Portanto, o caminho para desenvolver relações de negócios pode divergir muito de acordo com diferentes culturas, sistemas de crenças, e ainda com a infraestrutura institucional das sociedades. Não apenas os caminhos para a construção de relacionamento são diferentes, mas também a relativa importância dada aos atributos que compõem o grau de parentesco entre as pessoas o são.

\subsection{AS DIMENSÕES DO GUANXI}

Reconhecendo o impacto significativo do guanxi e sua influência sobre todos os negócios na sociedade empresarial chinesa, é importante para as empresas ocidentais identificar o quão forte é o seu guanxi, ou especificamente como medir a qualidade de guanxi entre a empresa e o seu parceiro chinês (Lee e Xu, 2001). A literatura existente indica que o conceito de guanxi tem sido discutido em termos de três construções estreitamente relacionadas, ganqing, renqing exinren (Hwang, 1987; Jacobs, 1979; Wang, 2007) e que esses três construtos são considerados coletivamente para refletir a qualidade de guanxi (Kipnis, 1997).

A primeira dimensão, qanqing, pode ser traduzida como "sentimentos" e implica no afeto e na emoção. De acordo com Chen e Chen (2004, p. 315):

Ganqing se refere ao grau de compreensão emocional, as conexões e a partilha de sentimentos de felicidade e de medo também. Além disso, refere-se a um sentimento de lealdade e de solidariedade, a vontade de cuidar um do outro em todas as circunstâncias.

Em chinês, ganqing é um termo frequentemente usado para descrever a qualidade de uma relação entre duas partes. Além disso, é utilizado para descrever os sentimentos entre diferentes tipos de relações (Kipnis, 1997). Por exemplo, quando é utilizado no contexto da família, um bom ganqing refere-se a boas ligações da família.

Semelhante ao guanxi, a maneira mais fácil de melhorar ganqing é por meio de interações sociais, ou seja, comer e beber juntos, visitar e participar de eventos próprios (Lee e Xu, 2001). Ao se realizarem atividades sociais em conjunto, há uma oportunidade 
para melhor nutrir ganqing e reforçar o guanxi, supondo que ambas as partes tenham gostado da ocasião. Isso explica a associação entre o guanxi e ganqing.

Nas relações de negócios, o conceito de ganqing está ligado ao vínculo social (Mavondo e Rodrigo, 2001), que representa o grau de amizade pessoal mútua e o gosto partilhado pelo comprador e vendedor, por exemplo. Em resumo, ganqing refere-se ao lado emocional do guanxi e pode ser estabelecido e melhorado por meio de interações sociais (Kipnis, 1997). Apesar de haver uma forte interdependência e mutualidade entre ganqing e guanxi, o ganqing não pode ser tomado como o único elemento do guanxi, pois esse é muito mais amplo do que os laços emocionais e também inclui outros atributos de suma importância, tais como as obrigações materiais e a troca de favores (Jacobs, 1979).

A segunda dimensão, renqing, é geralmente é traduzida como sensibilidade, simpatia, bondade humana, favoritismo e presente. No entanto, na prática, é frequentemente utilizada como "o tratamento especial de um indivíduo, a alocação de recursos para o outro como um ídomí no processo de uma transação de mercado, para reforçar os laços entre as partes" (Wong e Leung, 2001, p. 13). Renqing reflete reciprocidade, que é enfatizada na filosofia de Confúcio. É preciso seguir a regra da reciprocidade, como afirmado no antigo provérbio chinês: se alguém recebe uma gota de beneficência de outras pessoas, deve-se voltar a elas com uma fonte de beneficência (Hwang, 1987).

Pessoas que compartilham guanxi são especialmente ligadas por esta obrigação social de reciprocidade. Por exemplo, se um partido recebe um favor, ele deve renqing ao benfeitor e deve estar pronto para pagar, no futuro, uma vez que as circunstâncias o permitam (Yen et al., 2011). A fim de assegurar um guanxi saudável, um elevado valor é colocado sobre a obrigação de reciprocidade pelo chinês (Wang, 2007). No entanto, a prática da renqing não requer um retorno imediato. De acordo com Ambler (1995), os favores são retribuídos na hora certa. O receptor não deverá apressar-se em devolver o favor, ele deve armazená-lo durante o tempo que for preciso e devolvê-lo no momento certo, quando a outra parte precisar.

Todavia, o não pagamento do favor é considerado como imoral (Luo, 2001). Essa rejeição pode ferir os sentimentos do benfeitor original, bem como fazer a pessoa perder a face (mianzi). A face implica numa relação de status e reputação moral na sociedade chinesa e é também uma forma de autoimagem em termos de status social aprovado (Hwang, 1987).

De acordo com Yen et al. (2011), quanto maior a troca de favores, mais entrelaçadas e próximas tornam-se as duas partes. Isso explica por que renqing segue a regra restrita da reciprocidade numa base de longo prazo, pois sem a norma da reciprocidade, o guanxi deixa de ser uma vantagem nas relações interpessoais.

Além disso, vale destacar que, nos relacionamentos mantidos em uma rede guanxi, o mais forte hierarquicamente deve proteger o mais fraco que, em consequência dessa 
proteção, passa a dever favores, o que, em última instância, dá mais poder aos mais fortes na estrutura hierárquica do guanxi (Bastos e Pinto Neto, 2008).

A terceira dimensão, xinren, é uma palavra chinesa relativa à confiança. Além do ganqing e renqing, xinren é considerado um dos componentes mais importantes da guanxi e um constituinte essencial de qualquer parceria bem sucedida (Tsang, 1998). De acordo com Chen e Chen (2004), quanto maior o nível de confiança entre duas partes, melhor será o guanxi. Isso porque a confiança é tratada como de fundamental importância pelos chineses e é necessária na fase inicial de qualquer relacionamento comercial. Portanto, a confiança mútua deve ser estabelecida antes que qualquer transação possa ocorrer (Arregle et al., 2000).

Tendo isso em mente, quando se lida com os chineses, as empresas estrangeiras devem considerar a confiança como uma prioridade máxima em suas relações comerciais, pois, se não há confiança, o contrato formalizado é sem sentido (Ambler, 1995). $\mathrm{Na}$ verdade, para os chineses um contrato formal é mais susceptível de ser elaborado numa fase posterior, ou seja, após o estabelecimento de certo grau de confiança mútua, o que difere da visão ocidental de que um contrato deve ser finalizado antes de qualquer cooperação formal (Wong e Chan, 1999). Xinren, portanto, representa um dos elementos mais respeitados em relações comerciais chinesas, uma vez que ajuda a suavizar as operações e prevenir os riscos em um ambiente onde as normas legais, historicamente, não tendem a ser plenamente exercidas. A Tabela 2 resume o significado das três dimensões do guanxi.

Tabela 2 - As dimensões do guanxi

\begin{tabular}{l|l}
\hline \multicolumn{1}{c|}{ Dimensões } & \multicolumn{1}{c}{ Descrição } \\
\hline Ganqing & Sentimentos, afeição, ligação social, grau de amizade pessoal \\
\hline Xinren & Confiança, credibilidade e a benevolência entre os indivíduos \\
\hline Renqing & Troca de favores, reciprocidade. \\
\hline Fonte: Yen et al. (2011).
\end{tabular}

A análise do guanxi sob estas três dimensões possibilitou o desenvolvimento e validação de uma escala capaz de mensurar a qualidade do guanxi. Os pesquisadores Yen et al. (2011) construíram esta escala, fornecendo aos executivos uma ferramenta útil para avaliar os níveis de guanxi com seus parceiros chineses.

\section{GUANXI ENTRE INDIVÍDUOS VERSUS GUANXI ENTRE ORGANIZAÇÕES}

Guanxi é fundamentalmente uma relação entre indivíduos. Porém, como essas relações individuais podem ser transformadas em vantagem competitiva para a organização? 
O guanxi se torna um ativo organizacional apenas quando os indivíduos estão dispostos a usar o seu guanxi para alcançar objetivos organizacionais. Neste sentido, Standifird (2006) realizou uma pesquisa cujo objetivo foi explicar como o guanxi pode ser usado como um mecanismo para estabelecer a reputação corporativa na China.

De acordo com o autor, é difícil uma organização ter bom guanxi. No entanto, uma organização pode se estabelecer como respeitável por possuir um grande número de funcionários envolvidos em práticas de negócios baseados em guanxi. Indivíduos altamente conectados são parceiros de troca atraentes devido à sua rede de relações. A organização torna-se um parceiro de troca atraente na medida em que os indivíduos dentro dela estão bem ligados (Standfird, 2006). Quanto maior o número de indivíduos altamente conectados dentro da organização, maior a reputação da empresa.

A existência de indivíduos altamente ligados na mesma organização pode ter um efeito multiplicador na medida em que estes indivíduos estão ligados um ao outro. Standfird (2006) exemplifica a seguinte situação: A pessoa "A” dentro de uma organização tem 10 conexões importantes dentro da comunidade empresarial. A pessoa " $B$ ” dentro da mesma organização também possui 10 conexões importantes. Se "A" e "B" são bem ligados um ao outro, a organização terá acesso às 10 ligações de "A", além das 10 conexões de "B". O efeito é uma duplicação da influência de "A" por meio da ligação de "A" com "B". Ou seja, a ligação dos funcionários uns com os outros expande a qualidade do guanxi para as pessoas que trabalham dentro da mesma organização.

Standfird (2006) também ressalta que, só porque duas pessoas trabalham na mesma organização, não quer dizer que estes indivíduos tenham um bom guanxi um com o outro. O guanxi deve ser cultivado tanto dentro, quanto entre as organizações. No entanto, a conexão entre os indivíduos de uma organização pode ser um trunfo valioso para a empresa e para o indivíduo. Assim, é importante que a organização apóie explicitamente o desenvolvimento de guanxi entre os seus colaboradores por meio de eventos sociais, ou ainda que dedique certo número de horas de trabalho para a socialização explícita dos funcionários.

É importante promover guanxi entre os colaboradores para que a empresa mantenha pelo máximo de tempo possível esta rede de conexões. Se um funcionário decide deixar a organização, perde-se também o guanxi associado àquele indivíduo. Por isso, ter funcionários incorporados um ao outro reduz a probabilidade de esse querer deixar a organização, com medo de perder a "face" com os membros de sua rede guanxi (Standfird, 2006). Assim, por estimular a ligação dos funcionários uns com os outros, a organização não só melhora a qualidade do guanxi, mas também reduz a probabilidade de que o indivíduo deixe a organização. Outro aspecto importante é o apoio e a recompensa da organização aos funcionários para o desenvolvimento de guanxi e o seu uso para beneficiar a empresa (Park e Luo, 2001). 
O guanxi se torna um ativo organizacional apenas na medida em que os indivíduos estão dispostos a usar o seu guanxi em nome da organização. De acordo com Standifird (2006), o uso "egoísta” do guanxi deve ser desencorajado até o ponto de dissociação com os indivíduos que se recusam a compartilhar suas conexões com outros membros da organização. A falta de vontade de um indivíduo de compartilhar suas conexões com outras pessoas faz com que tais conexões tenham valor limitado para a organização.

Em resumo, guanxi é fundamentalmente um atributo individual que se torna um ativo organizacional quando os indivíduos estão dispostos a usar o seu guanxi para o benefício da organização. A existência de funcionários altamente ligados pode ter um efeito multiplicador na medida em que estejam conectados uns ao outros. As organizações devem apoiar explicitamente o desenvolvimento de guanxi entre os indivíduos, pois a sua reputação cresce à medida que os seus funcionários estejam bem conectados (tanto externa quanto internamente) e na medida em que essas conexões tornam-se associadas a importantes resultados organizacionais.

\subsection{COMO CONSTRUIR GUANXI}

A crescente aceitação e popularidade do guanxi no Ocidente tornaram ainda mais importante a compreensão conceitual desse fenômeno, motivando pesquisadores a analisar o seu impacto no desempenho e relacionamento da empresa e propor modelos sobre como desenvolver o guanxi. A pesquisa realizada por Chen e Chen (2004) sobre a construção do guanxi tem sido uma das obras mais relevantes sobre o assunto.

Os autores propõem o desenvolvimento do guanxi de acordo com três etapas: (1) início, (2) construção e (3) uso do guanxi. A Tabela 3 apresenta os três conjuntos de variáveis por etapa, apresentando inicialmente uma concepção integrada para desenvolver guanxi.

Tabela 3 - Processo de desenvolvimento do guanxi

\begin{tabular}{l|l|l|l}
\hline \multicolumn{1}{c|}{ Etapas } & \multicolumn{1}{c|}{ Objetivos } & \multicolumn{1}{c|}{ Atividades interativas } & Princípios de funcionamento \\
\hline Início & Criação das bases do guanxi & Familiarização & Auto-revelação mútua \\
\hline Construção & Aumento da qualidade do guanxi & $\begin{array}{l}\text { Interações expressivas e } \\
\text { instrumentais }\end{array}$ & Reciprocidade dinâmica \\
\hline Uso & $\begin{array}{l}\text { Obtenção dos benefícios, reavaliação } \\
\text { da qualidade do guanxi }\end{array}$ & Troca de favores & Equidade de longo prazo \\
\hline
\end{tabular}

Fonte: Chen e Chen (2004, p. 310).

Durante a primeira fase, dois indivíduos se familiarizam um com o outro por meio de uma autorrevelação mútua. Nesse processo, as duas partes buscam identificar pontos em comum - a criação das bases do guanxi. Chen e Chen (2004) alertam que as pessoas 
de culturas orientais, incluindo o chinês, não "quebram o gelo" facilmente com estranhos e não são tão socialmente desenvolvidos quanto os ocidentais, que rapidamente estabelecem contato com pessoas que não conhecem. Portanto, como um gesto de desejo em começar um relacionamento, as partes têm que mostrar vontade mútua de se autodivulgar, como se fossem velhos amigos (Chen e Chen, 2004). Dado o desejo de estabelecer bases para o futuro guanxi, a reciprocidade é um complemento essencial para a iniciativa de autorrevelação. Em qualquer caso, quanto maior a autorrevelação mútua, melhor a criação das bases do guanxi.

Uma iniciação bem sucedida leva para a segunda fase - a construção do guanxi. De acordo com Chen e Chen (2004), o objetivo dessa etapa é estabelecer a confiança mútua e o afeto para construir guanxi de qualidade. As atividades dessa etapa baseiam-se em interações expressivas e instrumentais. As interações expressivas referem-se a atividades sociais como festas, celebração de casamentos, nascimentos, aniversários, etc. As instrumentais estão relacionadas a atividades pragmáticas de trabalho e negócios, como ajuda mútua em encontrar emprego, atribuição de trabalho, troca de informações, cooperação no local de trabalho, transações comerciais, etc. Esses dois tipos de interações visam aproximação, ou seja, a melhoria da qualidade do guanxi em termos de construção da confiança, afeto e reciprocidade.

Depois de construído o guanxi, torna-se possível beneficiar-se do seu uso. Essa etapa é marcada pela troca de favores regulada pelo princípio da equidade de longo prazo. Este princípio defende que os indivíduos em uma situação de troca têm direito de partilhar o seu resultado de acordo com a sua contribuição no processo de troca. É possível que uma das partes peça a ajuda da outra parte continuamente por várias vezes; mas, até mesmo entre amigos íntimos e parentes, os esforços são feitos para lembrar conscientemente e manter o balanço social em equilíbrio no longo prazo (Yang, 1994).

Se um favor concedido de "A" para "B" excede as expectativas de "B”, então "A" terá um senso de equidade e o nível de qualidade guanxi será mantido ou melhorado. No entanto, quando um favor não é concedido conforme a expectativa, haverá um sentimento de desigualdade e a qualidade guanxi poderá ser prejudicada. Quando o resultado real é inferior à expectativa, pode haver uma sensação de traição e as duas partes poderão se afastar. A fim de proteger a qualidade do guanxi, o indivíduo que não conseguiu dar o favor pedido muitas vezes tenta provar o seu desejo ou sua relação de continuidade, proporcionando favores de outras formas ou em tempos futuros.

O modelo de Chen e Chen (2004) pode ser considerado um avanço significativo com relação às pesquisas sobre guanxi, pois retrata esse fenômeno como um processo dinâmico e de possível desenvolvimento, mesmo para os executivos ocidentais. A diferenciação dos atributos do guanxi não só facilita a sua construção, como 
também contribui para examinar os seus efeitos no relacionamento entre indivíduos e organizações.

\section{O IMPACTO DO GUANXI NAS ORGANIZAÇÕES}

Os chineses transformaram o guanxi em uma arte cuidadosamente calculada. Construir e manter guanxi são preocupações comuns entre empresários, gerentes, funcionários e até mesmo estudantes (Luo, 2001). Essa particularidade cultural é refletida, por exemplo, nos modelos de financiamentos informais na China. Sheng (2008) realizou uma pesquisa no Brasil que buscou analisar empiricamente os modelos de financiamento baseados em guanxi. Os resultados indicaram que os empreendedores utilizam guanxi para terem acesso ao financiamento e reduzirem o custo de crédito, e que participam de eventos sociais para manutenção e aquisição de guanxi no Brasil.

Outra pesquisa que comprovou empiricamente o papel do guanxi na realização de IDE foi a de Tong (2003), que constatou que a força das redes étnicas chinesas entre países parceiros está positivamente correlacionada com o montante recíproco acumulado de IDE entre os países. Esta relação não é limitada aos países do Sudeste Asiático, mas é aplicável a outros países incluídos no estudo, independentemente de investimentos provenientes de países industrializados ou de economias em desenvolvimento.

A relação do guanxi com o desempenho empresarial também foi evidenciada por Barnes et al. (2011). Os autores desenvolveram um modelo conceitual cujo objetivo foi incorporar e reunir os construtos de relacionamento ocidental e chinês a fim de melhorar as relações de negócios entre países anglo-saxões e a China. Para testar o modelo, os autores realizaram uma survey com importadores de Taiwan que mantinham relações comerciais com exportadores de países anglo-saxões (Reino Unido, Estados Unidos, Canadá, Irlanda, Austrália e Nova Zelândia). Os resultados confirmaram a significância de oito das nove hipóteses propostas, o que forneceu suporte empírico para o que o modelo conceitual revelasse que o guanxi é crucial para promover o desenvolvimento de relações de negócios entre países anglo-saxões e a China.

\section{CONSIDERAÇÕES FINAIS}

Com base na literatura apresentada, percebe-se que o guanxi não é um conceito simples, é uma regra não escrita e complexa que liga as relações sociais e de negócios na sociedade chinesa. Dentre as principais diferenças entre o guanxi e as abordagens de negócios ocidentais estão a percepção e o contexto da confiança e como essa se expressa em ambas as culturas. Na sociedade chinesa, a confiança é o fundamento e a principal orientação do guanxi, é o que dita como ele será conduzido e garante o seu 
funcionamento. Já na abordagem ocidental, que é focada em estratégias de transação com parceiros de negócio, a confiança incorpora a crença de que cada parte realizará o combinado conforme um contrato ou acordo escrito. Nesta abordagem, os atributos pessoais são removidos, o que é consistente com o ditado ocidental "você não pode misturar negócios com prazer".

Apesar das dificuldades em entender os traços da cultura chinesa e seus reflexos no modo de agir nas negociações, é importante ressaltar que essas dificuldades podem ser superadas. Para Chung (2005, p. 22) “a recomendação aos negociadores e expatriados é que não deixem nada à improvisação. Procurem estudar, antecipar, planejar e aprender rapidamente com suas experiências". Uma vez que os estrangeiros compreendam e respeitem as normas de conduta chinesa, poderão ser estabelecidos elos de negociação difíceis de serem quebrados. Por isso, o estudo e o conhecimento a respeito de todo aparato cultural que envolve a China devem ser entendidos como forma de obter vantagem competitiva no mercado chinês.

Por isso, tem-se a perspectiva de que o presente trabalho poderá contribuir para uma melhor compreensão sobre o que é guanxi e qual a sua influência nas relações internacionais, para que assim haja melhor aproveitamento dos recursos alocados internacionalmente tanto de estrangeiros na China quanto dos investidores chineses no ocidente. Sabe-se que são vários os aspectos que influenciam no sucesso das relações internacionais. No contexto da China, acredita-se que o guanxi seja um destes influenciadores.

\section{REFERÊNCIAS}

AMBLER, T. The derivation of guanxi. Marketing Management, v. 4, n. 1, p. 27, 1995.

ARREGLE, J. L.; BORZA, A.; DACIN, M. T.; HITT, M. A.; LEVITAS, E. Partner selection in emerging and developing market contexts: Resource-based and organizational learning perspectives. Academy of Management Journal, v. 43, n. 3, p. 449-467, 2000.

BASTOS, A.; PINTO NETO, A. E. S. Relações Públicas na China: o desafio do guanxi. Revista de Estudos da Comunicação, Curitiba, v. 9, n. 19, p. 113-122, maio/ago, 2008.

CHEN, M. J. Asian Management Systems: Chinese, Japanese and Korean Styles of Business. London and New York: Routledge, 1995, p. 52-66.

CHEN, M. J. Inside Chinese business: A guide for managers worldwide. Boston: Harvard Business School Press, 2001.

CHEN, X. P.; CHEN, C. C. On the intricacies of the Chinese Guanxi: A process model of Guanxi development. Asia Pacific Journal of Management, v. 21, p. 305-324, 2004.

CHUNG, T. Negócios com a China. Desvendando os segredos da cultura e estratégias da mente chinesa. São Paulo: Ed. Novo Século, 2005. 
CUNHA, A. M.; BICHARA, J.; MONSUETO, S. E.; LELIS, M. T. C. Impactos da ascensão da China sobre a economia brasileira: comércio e convergência cíclica. Revista de Economia Contemporânea, v. 15, n. 3, p. 406-440, 2011.

DAVIES, H.; LEUNG, K. P.; LUK, T. K.; WANG, Y. H. The benefits of Guanxi: the value of relationships in developing the Chinese market. Industrial Marketing Management, v. 24, p. 207-214, 1995.

DUNFEE, T. W.; WARREN, D. E. Is guanxi ethical? A normative analysis of doing business in China. Journal of Business Ethics, v. 32, n. 3, p. 191-204, 2001.

DUNNING, J. H.; KIM, C. The cultural roots of Guanxi: an exploratory study. World Economy, v. 30, n. 2, p. 329-341, 2007.

FEI, X. T. From the soil: the foundations of Chinese society. Berkeley: University of California Press, 1992.

FIORI, J. L. C. A nova geopolítica das nações e o lugar da Rússia, China, Índia, África do sul e Brasil. Oikos, Rio de Janeiro, v. 8, p. 1-20, 2007.

HWANG, K. K. Face and favor, the Chinese power game. The American Journal of Sociology, v. 92, p. 944-974, 1987.

JACOBS, B. J. A preliminary model of particularistic ties in Chinese political alliances: Kan-ch'ing nad Kuan-his a Rual Taiwanese township. China Quarterly, v. 78, June, p. 237-273, 1979.

KING, A. Y. Kuan-his and network building: A sociological interpretation. Daedalus, v. 120, p. 63-84, 1991.

KIPNIS, A. B. Producing Guanxi: sentiment, self, and subculture in a North China village. Durham: Duke University Press, 1997.

LEE, M.; XU, P. Doing business in China: the experience of Taiwanese businessman in various places of China. Taipei, Taiwan: Commercial Culture, 2001.

LEE, S. Y. Economics of Guanxi as an interpersonal investment game. Review of Development Economics, v. 14, n. 2, p. 333-342, 2010.

LO, M. C; OTIS, E. M. Guanxi civility: processes, potentials, and contingencies. Politics \& Society, v. 31, n. 1, p. 131-162, 2003.

LUO, Y. Guanxi and business. Singapore: World Scientific Publishing, 2001.

LUO, Y. Guanxi: principles, philosophies, and implications. Human Systems Management, v. 16, n. 1, p. 43-51, 1997.

MAVONDO, F. T.; RODRIGO, E. M. The effect of relationship dimensions on interpersonal and interorganizational commitment in organizations conducting business between Australia and China. Journal of Business Research, v. 52, p. 111-121, 2001.

PARK, S.; LUO, D. Guanxi and organizational dynamics: organizational networking in Chinese firms. Strategic Management Journal, v. 22, n. 5, p. 455-477, 2001.

PINHEIRO-MACHADO, R. Fazendo guanxi: dádivas, etiquetas e emoções na economia da China pós-Mao. MANA, v. 17, n. 1, p. 99-130, 2011. 
REDDING, G.; WONG, G. Y. Y. The psychology of Chinese organizational behavior. In: BOND, M. H. (Ed.) The Psychology of the Chinese People. New York: Oxford University Press, 1986, p. 213-266.

REDE NACIONAL DE INFORMAÇÕES SOBRE O INVESTIMENTO (RENAI). Anúncio de Investimentos Chineses no Brasil (2003 a 2011). Brasília: MDIC, 2011 Disponível em: <http:// www.mdic.gov.br/sistemas_web/renai/public/arquivo/arq1307386887.pdf>. Acesso em: 20 ago. 2012.

SHENG, H. H. Modelos de financiamento baseados em relaçőes pessoais: experiência de empreendedores chineses no Brasil. Revista de Administração Contemporânea, Curitiba, v. 12, n. 3, p. 741-761, Jul./Set., 2008.

STANDIFIRD, S. S. Using guanxi to establish corporate reputation in China. Corpoarte Reputation Review, v. 9, n. 3, p. 171-178, 2006.

TONG, S. Y. Ethnic Chinese networking in crossborder investment: the impact of economic and institutional development. Working Papers, Hong Kong Institute of Economics and Business Strategies, n. 1026, 2003. Disponível em: <http://www.hiebs.hku.hk/working_paper_updates/ pdf/wp1024b.pdf>. Acesso em: 20 mai. 2012.

TSANG, E. W. K. Can guanxi be a source of sustained competitive advantage for doing business in China? Academy of Management Executive, v. 12, p. 64-73, 1998.

WONG, Y. H., CHAN, R. Y. K. Relationship marketing in China: guanxi, favouritism and adaptation. Journal of Business Ethics, v. 22, n. 3, p. 107-108, 1999.

WONG, Y. H.; LEUNG, T. K. P. Guanxi relationship marketing in a Chinese context. New York: International Business Press, 2001.

YANG, M. M. Gifts, favors, and banquets: the art of social relationships in China. Ithaca, NY: Cornell University Press, 1994.

YEN, D.; BARNES, B. R.; WANG, C. L. The measurement of guanxi: introducing the GRX scale. Industrial Marketing Management. v. 40, p. 97-108, 2011.

YEUNG, I. Y. M.; TUNG, R. L. Achieving business success in Confucian societies: The importance of guanxi (connections). Organizational Dynamics, v. 25, n. 2, p. 54-65, 1996.

ZHAN, J.; PIMPA, N. Embracing guanxi: the literature review. International Journal of Asian Business and Information Management, v. 1, n. 1, p. 23-31, Jan./Mar., 2010. 